\title{
Desafios na gestão de medicamentos de alto preço no SUS: avaliação da Assistência Farmacêutica em São Paulo, Brasil
}

\author{
Challenges in the management of high-priced drugs in the SUS: \\ evaluation of Pharmaceutical Policy in São Paulo, Brazil
}

Karina de Oliveira Fatel (https://orcid.org/0000-0002-2256-4988) ${ }^{1}$

Marina Raijche Mattozo Rover (https://orcid.org/0000-0002-2123-4493) ${ }^{2}$

Samara Jamile Mendes (https://orcid.org/0000-0003-3107-8233) ${ }^{3}$

Silvana Nair Leite (https://orcid.org/0000-0002-5258-9684) ${ }^{2}$

Silvia Storpirtis (https://orcid.org/0000-0001-6156-6890) ${ }^{3}$
${ }^{1}$ Coordenadoria de Assistência Farmacêutica, Secretaria da Saúde do Estado de São Paulo. Av. Dr. Enéas de Carvalho Aguiar $1887^{\circ}$ andar, 05403000. São Paulo SP Brasil. karinafatel@gmail.com ${ }^{2}$ Departamento de Ciências Farmacêuticas, Centro de Ciências da Saúde, Universidade Federal de Santa Catarina. Florianópolis SC Brasil. ${ }^{3}$ Faculdade de Ciências Farmacêuticas, Universidade de São Paulo. São Paulo SP Brasil.

\begin{abstract}
The aim of this study is to evaluate the management capacity of the Specialized Component of Pharmaceutical Services (CEAF, in Portuguese) in the state of São Paulo (SP), according to the organizational, operational and sustainability aspects. The study was designed as an evaluative investigation, with the adoption of a theoretical model and protocol of indicators developed for application at the national level and validated (Nominal Group and Traditional Committee) for application in the reality of the SP. The data collection in the 35 CEAF units was carried out in 2017 and 2018, and covered all technical areas that participate in the management/execution of CEAF, in both its central and regional scopes. The assessment of management capacity was based on a critical analysis of the obtained results, analyzing their strengths and weaknesses. After collecting data from 35 CEAF units, it was found that the management capacity was positive in the operational dimension with challenges concentrated in the other dimensions. The results showed greater investments and development in the technical aspects of pharmaceutical services, but deficiencies in such areas as the monitoring of clinical results, infrastructure, regulation, and communication with the actors involved.

Key words Health Services Research, Population Health Management, Pharmaceutical Services, High-cost drugs
\end{abstract}

Resumo O objetivo deste estudo foi avaliar a capacidade de gestão do Componente Especializado da Assistência Farmacêutica (CEAF) no estado de São Paulo (ESP), sob os aspectos organizacional, operacional e sustentabilidade. O desenho do estudo foi uma investigação avaliativa, com adaptação de um modelo teórico e protocolo de indicadores desenvolvido para aplicação em âmbito nacional, e validado (Grupo Nominal e Comitê Tradicional) para a aplicação na realidade do ESP. A coleta de dados, em 35 unidades, foi realizada em 2017 e 2018 e contemplou todas as áreas que participam da gestão/execução do CEAF do estado, em seu âmbito central e regional. A avaliação da capacidade de gestão foi fundamentada na análise crítica dos resultados obtidos, analisando suas fragilidades e as potencialidades. Verificou-se que a capacidade de gestão foi positiva na dimensão operacional, com desafios concentrados nas demais dimensões. Os resultados demonstraram maiores investimentos e desenvolvimento em aspectos técnicos da assistência farmacêutica, mas deficitárias em relação a aspectos como: monitoramento de resultados clinicos, regulamentação, infraestrutura e comunicação com os atores envolvidos.

Palavras-chave Avaliação em saúde, Gestão em saúde, Assistência Farmacêutica, Politica Nacional de Assistência Farmacêutica, Medicamentos do Componente Especializado da Assistência Farmacêutica 


\section{Introdução}

No Brasil, o acesso aos medicamentos de mais alto preço é dependente de um conjunto de ações e articulações que envolvem as três esferas de governo. Dos três componentes da Assistência Farmacêutica (AF), a saber, Componente Básico da Assistência Farmacêutica (CBAF), Estratégico (CEsAF) e Especializado (CEAF), este último é o que contempla os medicamentos de preços mais elevados disponibilizados pelo Sistema Único de Saúde (SUS). O CEAF é definido como uma estratégia de acesso a medicamentos para a garantia da integralidade dos tratamentos, cujas linhas de cuidado estão definidas em Protocolos Clínicos e Diretrizes Terapêuticas (PCDT). Em seu âmbito é que se estabelece a maior parte das tensões entre o aumento dos gastos, a pressão da demanda e a competição comercial em relação aos medicamentos ${ }^{1-3}$.

A aquisição de medicamentos representa uma parcela importante dos gastos totais em saúde e a disponibilidade de medicamentos de alto preço tem grande impacto social e relevância terapêutica, além de exigirem serviços especializados para sua efetivação $0^{3-5}$.

Apesar da ênfase expressa na literatura brasileira e entre os gestores aos aspectos financeiros do CEAF, diferentes desafios compõem um contexto complexo a ser administrado, visando o acesso integral e universal aos medicamentos ${ }^{3,6}$. Um destes desafios é a descentralização das ações, a partir da qual os estados e municípios passaram a assumir a responsabilidade direta pela atenção à saúde, incluindo as ações relacionadas à $\mathrm{AF}^{6}$.

A gestão do CEAF apresenta desafios importantes no atendimento tempestivo das necessidades dos usuários, na relação com os demais serviços de saúde, além de questões de infraestrutura e processos de serviços ${ }^{3,4,6}$ Para responder a estes desafios, a investigação de políticas e serviços de saúde cumpre um papel fundamental ao possibilitar a identificação de problemas relevantes, e a provisão de informação confiável, constituindo uma importante ferramenta para guiar a gestão na melhoria da qualidade dos serviços ${ }^{7}$.

No campo da AF, proposições ampliadas de gestão e avaliação foram apresentadas por Barreto $^{8}$ e Barreto e Guimarães?. Baseadas no referencial de Carlos Matus ${ }^{10}$ e Guimarães et al. ${ }^{11}$, sustentam que gestão é um processo técnico, político e social capaz de produzir resultados; e que capacidade de gestão é a capacidade de uma organização em decidir com autonomia, flexibilidade e transparência mobilizando recursos e construin- do a sustentabilidade dos resultados de gestão ${ }^{11}$ (p.1646). A partir de tais conceitos, avaliações da capacidade de gestão da AF foram desenvolvidas no nível municipal e estadual numa perspectiva abrangente, para além de estruturas e processos técnicos ${ }^{6,8,12}$.

Com base nestes referenciais, a capacidade de gestão é avaliada por meio de três dimensões interdependentes: organizacional, operacional e sustentabilidade. A organizacional revela aspectos relacionados à capacidade de planejar e decidir de forma participativa, autônoma e transparente. A operacional revela a capacidade de manter e ampliar os recursos logísticos e gerenciais. A sustentabilidade revela a capacidade de sustentar os resultados da gestão, contemplando aspectos relacionados à institucionalização de mecanismos e estratégias que ampliam e/ou consolidam apoios e alianças capazes de favorecer a sustentabilidade das decisões e dos resultados pretendidos pela gestão?

O estado de São Paulo (ESP), que concentra $21 \%$ da população brasileira, também enfrenta desafios de gestão em $\mathrm{AF}^{13}$. Neste, o CEAF representa uma das áreas de maior impacto financeiro, com tendência de aumento ${ }^{13}$. Em 2015, os investimentos em medicamentos do CEAF ultrapassaram $R \$ 1.5$ bilhão, dos quais mais de $R \$ 150$ milhões foram financiados pelo estado ${ }^{14-16}$.

Neste contexto, é cada vez maior a necessidade de avanço na capacidade de gestão para superar as adversidades e responder adequadamente as necessidades da população. Ainda, cabe destacar que o desenvolvimento de estudos avaliativos do CEAF são bastante recentes ${ }^{6}$.

Assim, tendo o desafio de buscar subsídios para qualificar a AF e ampliar a disponibilidade de dados sobre o acesso aos medicamentos de alto preço, este estudo foi conduzido com o objetivo de avaliar a capacidade de gestão do CEAF no ESP.

\section{Metodologia}

Trata-se de um estudo avaliativo, realizado de junho de 2016 a fevereiro de 2018. Foram utilizados os modelos lógico e teórico, o protocolo de indicadores e os formulários de coleta de dados desenvolvidos por Rover et al. ${ }^{6,17,18}$, após adaptação. O protocolo de indicadores é composto de: oito indicadores organizacionais (80 pontos), 11 operacionais (110 pontos) e seis de sustentabilidade (60 pontos) $)^{6,18}$. 


\section{Local do estudo e sujeitos da pesquisa}

O projeto foi desenvolvido na Secretaria Estadual da Saúde de São Paulo (SES/SP), em seu âmbito central (direção do CEAF) e regional (Almoxarifado Central e Farmácias de Medicamentos Especializados - FME).

Os sujeitos de pesquisa envolvidos, doravante chamados de equipe de especialistas, foram selecionados por conveniência, para cada etapa, segundo os critérios:

Validação do modelo teórico e protocolo de indicadores: Profissionais com amplo conhecimento e experiência na AF do ESP, atuantes no ensino, na pesquisa, na gestão e/ou na assistência, com envolvimento direto ou indireto no CEAF; Disponibilidade de participação nas duas fases do estudo: validação dos instrumentos on-line e comparecimento na oficina de consenso (presencial).

Validação aparente dos formulários de coleta de dados e na etapa de aplicação dos mesmos: Profissionais responsáveis (ou corresponsáveis) pelas FME e Almoxarifado Central da SES/SP e gestor (nível central) dos Componentes da AF e do CEAF da SES/SP; Disponibilidade de resposta do formulário de coleta de dados.

A Figura 1 exemplifica por etapa da pesquisa, a quantidade e a atuação dos sujeitos acima descritos.

\section{Adaptação dos Instrumentos de pesquisa}

\section{Adaptação e validação do modelo teórico e protocolo de indicadores}

Fez-se necessária a adaptação do modelo teórico e protocolo de indicadores, desenvolvido por Rover et al. ${ }^{6,18}$, considerando as variáveis funcionais do CEAF no ESP. A adaptação do protocolo de indicadores levou em conta que o indicador só é válido no contexto específico no qual se processa a avaliação ${ }^{19}$. Os indicadores foram adaptados quanto a sua pergunta, medida, pontuação, parâmetros, fonte de coleta de dados e peso.

Para a validação de conteúdo foram utilizadas as técnicas: Grupo Nominal (TGN) e Comitê Tradicional. Seguiram-se as seguintes fases:

Fase I - TGN - etapa on-line:

Os especialistas receberam o modelo teórico e o protocolo de indicadores adaptados, bem como fundamentos teóricos que levaram à sua elaboração. Os documentos foram organizados em formulários e disponibilizados através de um endereço eletrônico, contando com o suporte do aplicativo do Google ${ }^{\circledR}$ - Google Forms e exportado para o software Microsoft Excel ${ }^{\circledR}$ para as análises.

Os formulários elaborados foram divididos em quatro partes. O primeiro formulário correspondia à análise do modelo teórico adaptado, quanto à sua "pertinência" ${ }^{20}$. No segundo, terceiro e quarto formulários os especialistas avaliaram a qualidade dos indicadores adaptados quanto a sua pergunta, medida, parâmetro, fonte de dados e pontuação, utilizando os atributos: Clareza; Validade/efetividade; Relevância; Acessibilidade/ mensurabilidade ${ }^{20,21}$. Para pontuação, foi utilizada uma escala tipo Likert de cinco pontos ${ }^{22}$. Ainda, foram inseridos campos abertos para justificativa (quando a nota do especialista fosse inferior a 3 pontos) e para propostas de melhoria (independente do ponto atribuído).

Com os dados tabulados calculou-se a média de pontos atribuídos, sendo considerados aprovados os que apresentaram média de 4 ou mais pontos. Os indicadores que, em média, tiveram pontuação igual ou inferior a 3,9, em qualquer um dos atributos, foram levados para discussão na oficina de consenso (fase II).

As sugestões de melhoria propostas pelos especialistas para aperfeiçoamento do modelo teórico e indicadores, independente da pontuação recebida, foram avaliadas e, quando pertinentes, foram aceitas e incorporadas. As que impactavam significativamente o modelo ou indicador, independente de já ter sido aprovado na fase I, foram levadas para discussão na fase II.

Fase II - Técnica de Comitê Tradicional:

Consistiu na realização de uma oficina presencial de 8 horas, utilizando-se da técnica de consenso "Comitê Tradicional". No primeiro momento, foram revisados os conceitos teóricos que fundamentaram a construção ${ }^{23}$ do protocolo de indicadores. No segundo momento, foram apresentados os indicadores que obtiveram média igual ou inferior a 3,9 e os indicadores que foram aprovados, mas que receberam sugestões de melhoria impactantes no conteúdo. Os especialistas discutiram as questões apresentadas, até a obtenção de consenso quanto à permanência (com ou sem ajustes) ou exclusão do indicador. No terceiro momento, foram rediscutidos os parâmetros e os pesos de todos os indicadores, possibilitando ajustes e adaptações.

Os especialistas receberam, após todos os ajustes, as versões validadas. 


\section{ETAPAS DE DESENVOLVIMENTO DA PESQUISA}

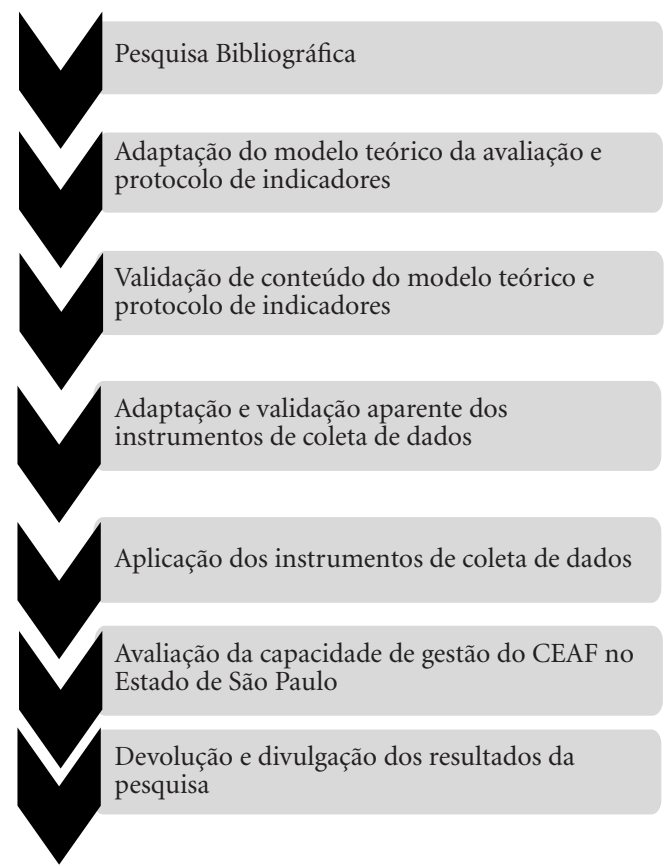

SUJEITOS DE PESQUISA

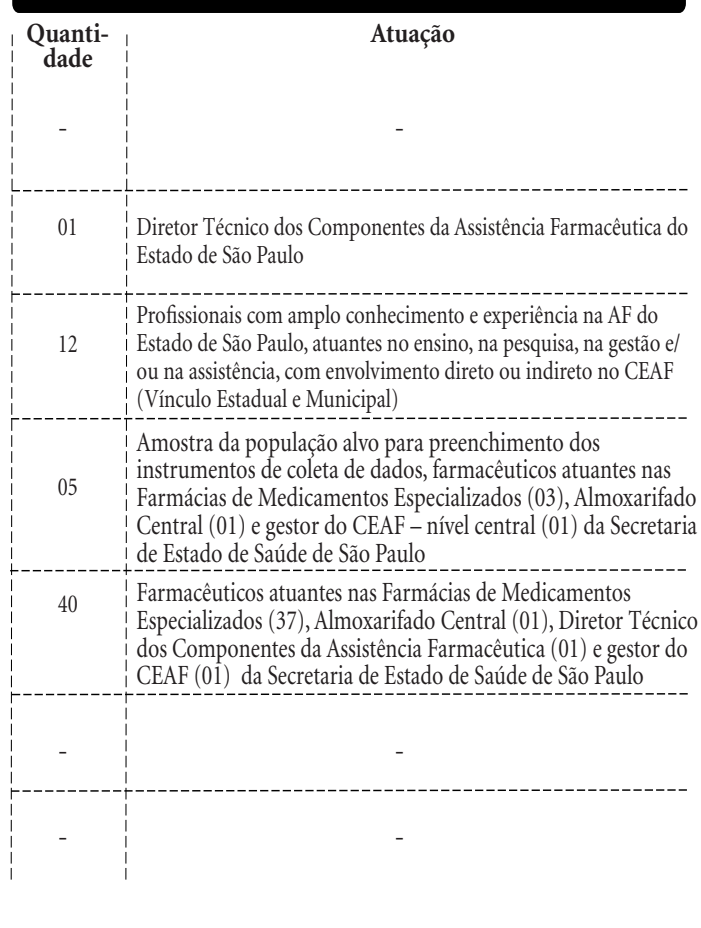

Figura 1. Etapas de desenvolvimento da pesquisa e sujeitos envolvidos em cada uma das etapas.

Fonte: Elaborado pelas autoras.

\section{Adaptação e validação aparente dos instrumentos de coleta de dados}

A adaptação inicial dos instrumentos de coleta de dados foi realizada pela pesquisadora (primeira autora), com base nos documentos validados na etapa anterior.

Os instrumentos adaptados são: (a) Formulário de coleta de dados com o GESTOR (nível central); (b) Formulário de coleta de dados com FARMÁCIAS (nível regional); (c) Formulário de coleta de dados com ALMOXARIFADO CENTRAL da SES/SP. O instrumento (a) foi elaborado em software Microsoft Word ${ }^{\circledR}$, e os instrumentos (b) e (c) foram organizados em formulários do Google ${ }^{\circledR}$ - Google Forms.

Após adaptação, os instrumentos foram apresentados à equipe gestora do CEAF da SES/SP, que validou o conteúdo por consenso e emitiu o aval para o início da validação aparente (layout e compreensão do formulário) e posterior coleta de dados.

A pesquisadora e a equipe gestora do CEAF da SES/SP definiram que a validação aparente, dos instrumentos de coleta de dados, seria realizada com:

O gestor do CEAF (nível central) - assessor responsável pelo CEAF;

O farmacêutico responsável de $3 \mathrm{FME}$ - uma na capital e de grande porte (gestão por Organização Social de Saúde - OSS); uma na Grande São Paulo e de pequeno porte (gestão direta); e outra no interior do ESP de grande porte (gestão por OSS);

O farmacêutico responsável do Almoxarifado Central.

Esta etapa ocorreu como última fase do Comitê tradicional.

\section{Aplicação dos instrumentos de coleta de dados}

A coleta de dados foi realizada de dezembro/2017 a janeiro/2018 e contemplou todas as áreas que participam da gestão/execução do CEAF vinculados à SES/SP, em seu âmbito central (direção do CEAF) e regional (Almoxarifado Central e 37 FME). 
O formulário de coleta de dados para o GESTOR foi enviado por e-mail e os formulários de coleta de dados das FARMÁCIAS E ALMOXARIFADO CENTRAL foram disponibilizados através de um endereço eletrônico, contando com o suporte do aplicativo do Google ${ }^{\circledR}$ - Google Forms.

\section{Avaliação da capacidade de gestão do CEAF no estado de São Paulo}

Com as informações coletadas foi possível o preenchimento do protocolo de indicadores validado (Quadro 1). A avaliação da capacidade de gestão do CEAF no ESP foi fundamentada na análise crítica dos resultados obtidos, analisando as fragilidades e as potencialidades do desenvolvimento da gestão estadual do CEAF.

A atribuição de um juízo de valor de cada indicador e para cada dimensão foi baseada nos parâmetros validados pela equipe de especialistas e foram convertidos em cores, facilitando a visualização dos resultados obtidos, conforme apresentado no Quadro ${ }^{23}$.

A pesquisa foi aprovada pelo Comitê de Ética em Pesquisa da Faculdade de Ciências Farmacêuticas da Universidade de São Paulo (CEP/FCF/USP), sob Parecer elaborado em 26 de setembro de 2016.

Quadro 1. Resultados da avaliação da capacidade de gestão do Componente Especializado da Assistência Farmacêutica do Estado de São Paulo, por indicador e dimensão.

\begin{tabular}{|c|c|c|c|c|c|}
\hline Indicadores & $\begin{array}{l}\text { Significado do } \\
\text { Indicador }\end{array}$ & $\begin{array}{l}\text { Pontuação } \\
\text { máxima }\end{array}$ & Resultado da Avaliação & $\begin{array}{l}\text { Pontos } \\
\text { obtidos }\end{array}$ & \begin{tabular}{|c} 
Cor do \\
indicador
\end{tabular} \\
\hline \multicolumn{6}{|c|}{ Dimensão Organizacional } \\
\hline \multirow[t]{2}{*}{ 1. Participação } & \multirow{2}{*}{$\begin{array}{l}\text { Participação de } \\
\text { gestores em órgãos } \\
\text { de participação } \\
\text { social e existência } \\
\text { de instâncias } \\
\text { que permitam a } \\
\text { participação dos } \\
\text { atores envolvidos }\end{array}$} & 10 & $\begin{array}{l}\text { Participou de } 3 \text { ou mais instâncias: } \\
\text { CES, CIB, Reuniões para a } \\
\text { elaboração/monitoramento do PES, } \\
\text { Reuniões técnicas do CONASS }\end{array}$ & \multirow[t]{2}{*}{7,5} & \multirow[t]{2}{*}{ Verde } \\
\hline & & & $\begin{array}{l}\text { A gestão estadual desenvolveu } \\
\text { estratégias ou criou instâncias } \\
\text { para a participação dos envolvidos } \\
\text { no CEAF: uma estratégia com } \\
\text { associação de pacientes }\end{array}$ & & \\
\hline \multirow[t]{2}{*}{ 2. Transparência } & \multirow{2}{*}{$\begin{array}{l}\text { Divulgação de } \\
\text { informações } \\
\text { sobre as faltas de } \\
\text { medicamentos e dos } \\
\text { preços praticados } \\
\text { na compra dos } \\
\text { medicamentos }\end{array}$} & 10 & $\begin{array}{l}\text { A gestão estadual desenvolveu } \\
\text { estratégias ou criou instâncias } \\
\text { para a participação dos envolvidos } \\
\text { no CEAF: uma estratégia com } \\
\text { associação de pacientes }\end{array}$ & \multirow[t]{2}{*}{5,0} & \multirow[t]{2}{*}{ Amarelo } \\
\hline & & & $\begin{array}{l}\text { Há divulgação dos preços } \\
\text { praticados pelo Estado na compra } \\
\text { dos medicamentos (grupo 1B e } \\
2^{1} \text { ) do CEAF para a população } \\
\text { por intermédio do Sistema } \\
\text { informatizado Farmanet (online) }\end{array}$ & & \\
\hline \multirow[t]{2}{*}{ 3. Planejamento } & \multirow{2}{*}{$\begin{array}{l}\text { Inclusão de ações } \\
\text { do CEAF no PES. } \\
\text { Existência de reuniões } \\
\text { de planejamento } \\
\text { específicas do CEAF }\end{array}$} & 10 & $\begin{array}{l}\text { Existem no PES ações específicas } \\
\text { relacionadas a AF que envolvem } \\
\text { questões do CEAF }\end{array}$ & \multirow[t]{2}{*}{5,0} & \multirow[t]{2}{*}{ Amarelo } \\
\hline & & & $\begin{array}{l}\text { Gestores do CEAF não realizam } \\
\text { reuniões de planejamento estratégico }\end{array}$ & & \\
\hline $\begin{array}{l}\text { 4. Monitoramento e } \\
\text { avaliação das ações }\end{array}$ & $\begin{array}{l}\text { Existência de } \\
\text { indicadores e } \\
\text { a utilização do } \\
\text { monitoramento } \\
\text { destes para o } \\
\text { planejamento das } \\
\text { ações }\end{array}$ & 10 & $\begin{array}{l}\text { Os indicadores para o } \\
\text { monitoramento das ações } \\
\text { relacionadas ao CEAF não são } \\
\text { utilizados para o planejamento das } \\
\text { ações ou não possui indicadores de } \\
\text { monitoramento }\end{array}$ & 0,0 & Vermelho \\
\hline
\end{tabular}


Quadro 1. Resultados da avaliação da capacidade de gestão do Componente Especializado da Assistência Farmacêutica do Estado de São Paulo, por indicador e dimensão.

\begin{tabular}{|c|c|c|c|c|c|}
\hline Indicadores & $\begin{array}{l}\text { Significado do } \\
\text { Indicador }\end{array}$ & $\begin{array}{c}\text { Pontuação } \\
\text { máxima }\end{array}$ & Resultado da Avaliação & $\begin{array}{l}\text { Pontos } \\
\text { obtidos }\end{array}$ & \begin{tabular}{|c} 
Cor do \\
indicador
\end{tabular} \\
\hline 5. Parcerias & $\begin{array}{l}\text { Parcerias com outras } \\
\text { instituições para o } \\
\text { desenvolvimento de } \\
\text { atividades do CEAF }\end{array}$ & 10 & $\begin{array}{l}\text { Existem parcerias com outras } \\
\text { instituições para desconcentrar o } \\
\text { atendimento aos pacientes, sendo } \\
\text { que algumas parcerias não são } \\
\text { formalizadas }\end{array}$ & 5,0 & Amarelo \\
\hline \multirow[t]{2}{*}{ 6. Regulamentação } & \multirow{2}{*}{$\begin{array}{l}\text { Existência de fluxos } \\
\text { regulamentados } \\
\text { para a avaliação } \\
\text { das solicitações e } \\
\text { diretrizes sobre os } \\
\text { processos de trabalho } \\
\text { nas unidades }\end{array}$} & 10 & $\begin{array}{l}\text { Não há fluxo estabelecido } \\
\text { (documentado) para avaliação das } \\
\text { solicitações de medicamentos do } \\
\text { CEAF no Estado }\end{array}$ & \multirow[t]{2}{*}{0,0} & \multirow[t]{2}{*}{ Vermelho } \\
\hline & & & $\begin{array}{l}\text { Há diretrizes estabelecidas } \\
\text { (documentadas) dos processos de } \\
\text { trabalho, apenas para uma etapa } \\
\text { de execução }{ }^{2} \text {, nas unidades que } \\
\text { desenvolvem atividades do CEAF }\end{array}$ & & \\
\hline 7. Institucionalização & $\begin{array}{l}\text { Existência de } \\
\text { uma instância } \\
\text { institucionalizada } \\
\text { responsável por todas } \\
\text { as atividades do } \\
\text { CEAF }\end{array}$ & 10 & $\begin{array}{l}\text { Existe na estrutura administrativa da } \\
\text { SES uma instância institucionalizada } \\
\text { (e formalizada por meio de } \\
\text { publicação) relacionada a AF cujas } \\
\text { competências envolvem apenas } \\
\text { questões técnicas da gestão do } \\
\text { CEAF. Questões Administrativas são } \\
\text { tratadas por outra coordenadoria. }\end{array}$ & 5,0 & Amarelo \\
\hline $\begin{array}{l}\text { 8. Acesso } \\
\text { descentralizado }\end{array}$ & $\begin{array}{l}\text { Atendimento dos } \\
\text { usuários em seus } \\
\text { municípios de } \\
\text { residência }\end{array}$ & 10 & $\begin{array}{l}\text { As atividades do CEAF } \\
\text { relacionadas ao atendimento } \\
\text { dos usuários (solicitações, } \\
\text { renovações, dispensações) estão } \\
\text { desconcentrados/descentralizados } \\
\text { para 95\% dos municipios do Estado, } \\
\text { de modo a atendê-los no seu próprio } \\
\text { município de residência (unidades } \\
\text { estaduais e/ou municipais) }\end{array}$ & 10,0 & Verde \\
\hline \multicolumn{2}{|l|}{ Resultado da Dimensão } & 80 & - & 37,5 & Laranja \\
\hline
\end{tabular}

\section{Resultados}

O modelo teórico adaptado e validado para a realidade do ESP é apresentado na Figura 2.

$\mathrm{O}$ protocolo de indicadores validado para o ESP apresentou poucas alterações em relação ao protocolo utilizado como referência. As maiores adaptações foram realizadas nas medidas, para expressassem com maior fidedignidade a realidade do ESP.

Os ajustes nas medidas foram categorizados como "temporalidade" - delimitação da medida em um determinado período de tempo; "escrita da pergunta" - ajustes de escrita da pergunta da medida visando a melhor compreensão e clareza do que está sendo medido e/ou ajustes de semânti- ca; "parâmetro" - alteração, ampliação ou redução dos parâmetros utilizados para atribuir pontuação à medida; "medida" - ajustes ou alteração da medida do indicador; "coleta de dados" - alteração, ampliação ou redução das fontes de coleta de dados a serem consultadas para aplicação da medida. Ainda, houve realocação de uma medida do indicador "Financiamento" para o indicador "Programação/Aquisição de medicamentos", ao entender que praticar a desoneração de tributos ou aplicar o coeficiente de adequação de preços implica mais na capacidade de adquirir o medicamento com descontos do que efetivamente na capacidade de garantir o financiamento para o CEAF.

Dos ajustes realizados no protocolo de indicadores, 84 foram realizados na dimensão ope- 
Quadro 1. Resultados da avaliação da capacidade de gestão do Componente Especializado da Assistência Farmacêutica do Estado de São Paulo, por indicador e dimensão.

\begin{tabular}{|c|c|c|c|c|c|}
\hline Indicadores & $\begin{array}{l}\text { Significado do } \\
\text { Indicador }\end{array}$ & $\begin{array}{c}\text { Pontuação } \\
\text { máxima }\end{array}$ & Resultado da Avaliação & $\begin{array}{l}\text { Pontos } \\
\text { obtidos }\end{array}$ & $\begin{array}{c}\text { Cor do } \\
\text { indicador }\end{array}$ \\
\hline \multicolumn{6}{|c|}{ Dimensão Operacional } \\
\hline 1. Comunicação & $\begin{array}{l}\text { Comunicação entre } \\
\text { as unidades }\end{array}$ & 10 & $\begin{array}{l}\text { 53\% das unidades - FME e } \\
\text { Almoxarifado Central - avaliam a } \\
\text { comunicação com a equipe central } \\
\text { como boa ou muito boa (notas } 4 \\
\text { ou 5) }\end{array}$ & 5,0 & Amarelo \\
\hline \multirow[t]{2}{*}{$\begin{array}{l}2 . \\
\text { Complementariedade }\end{array}$} & \multirow[t]{2}{*}{$\begin{array}{l}\text { Preocupação com } \\
\text { o atendimento das } \\
\text { linhas de cuidados }\end{array}$} & \multirow[t]{2}{*}{10} & $\begin{array}{l}\text { Não existe pactuação de } \\
\text { medicamentos chave (elenco } \\
\text { mínimo do grupo } 3 \text { do CEAF) para a } \\
\text { primeira linha de cuidado }\end{array}$ & \multirow[t]{2}{*}{5,0} & \multirow[t]{2}{*}{ Amarelo } \\
\hline & & & $\begin{array}{l}\text { É realizada a formalização de APAC } \\
\text { na dispensação dos medicamentos } \\
\text { do Grupo } 2\end{array}$ & & \\
\hline \multirow[t]{6}{*}{$\begin{array}{l}\text { 3. Condições } \\
\text { normativas }\end{array}$} & \multirow{6}{*}{$\begin{array}{l}\text { Unidades com } \\
\text { condições legais } \\
\text { e sanitárias para } \\
\text { o exercício das } \\
\text { atividades }\end{array}$} & \multirow[t]{6}{*}{10} & $\begin{array}{l}\text { 50\% das unidades (FME e } \\
\text { Almoxarifado Central) possuem } \\
\text { alvará sanitário atualizado }\end{array}$ & \multirow[t]{6}{*}{1,8} & \multirow[t]{6}{*}{ Vermelho } \\
\hline & & & $\begin{array}{l}\text { A gestão estadual não monitora } \\
\text { a atualização do alvará sanitário } \\
\text { das unidades que movimentam } \\
\text { medicamentos do CEAF }\end{array}$ & & \\
\hline & & & $\begin{array}{l}\text { 44\% das unidades (FME e } \\
\text { Almoxarifado Central) possuem } \\
\text { PGRSS atualizado }\end{array}$ & & \\
\hline & & & $\begin{array}{l}\text { A gestão estadual não monitora a } \\
\text { atualização do PGRSS das unidades } \\
\text { que movimentam medicamentos do } \\
\text { CEAF }\end{array}$ & & \\
\hline & & & $\begin{array}{l}\text { 68\% das unidades (FME e } \\
\text { Almoxarifado Central) possuem } \\
\text { certidão de regularidade técnica } \\
\text { junto ao CRF atualizada }\end{array}$ & & \\
\hline & & & $\begin{array}{l}\text { A gestão estadual não monitora } \\
\text { a atualização da certidão de } \\
\text { regularidade técnica do CRF } \\
\text { das unidades que movimentam } \\
\text { medicamentos do CEAF }\end{array}$ & & \\
\hline \multirow[t]{2}{*}{ 4. Infraestrutura } & \multirow[t]{2}{*}{$\begin{array}{l}\text { Existência de } \\
\text { investimentos e } \\
\text { condições mínimas } \\
\text { de infraestrutura nas } \\
\text { unidades }\end{array}$} & \multirow[t]{2}{*}{10} & $\begin{array}{l}\text { Não está contemplado no PPA } \\
\text { vigente investimento para } \\
\text { infraestrutura de farmácias } \\
\text { (que inclua às que dispensam } \\
\text { medicamentos do CEAF) }\end{array}$ & \multirow[t]{2}{*}{1,3} & \multirow[t]{2}{*}{ Vermelho } \\
\hline & & & $\begin{array}{l}\text { 35\% das unidades (FME e } \\
\text { Almoxarifado Central) afirmam } \\
\text { possuir } 75 \% \text { ou mais dos itens } \\
\text { necessários de infraestrutura }\end{array}$ & & \\
\hline $\begin{array}{l}\text { 5. Polos de Aplicação } \\
\text { de Medicamentos/SR }\end{array}$ & $\begin{array}{l}\text { Existência de SR nas } \\
\text { diversas regiões do } \\
\text { Estado }\end{array}$ & 10 & $\begin{array}{l}\text { 64\% das unidades afirmam possuir } \\
75 \% \text { ou mais dos SR ou Pólos } \\
\text { de Aplicação de Medicamentos } \\
\text { pesquisados }\end{array}$ & 5,0 & Amarelo \\
\hline
\end{tabular}


Quadro 1. Resultados da avaliação da capacidade de gestão do Componente Especializado da Assistência Farmacêutica do Estado de São Paulo, por indicador e dimensão.

\begin{tabular}{|c|c|c|c|c|c|}
\hline Indicadores & $\begin{array}{l}\text { Significado do } \\
\text { Indicador }\end{array}$ & $\begin{array}{l}\text { Pontuação } \\
\text { máxima }\end{array}$ & Resultado da Avaliação & $\begin{array}{l}\text { Pontos } \\
\text { obtidos }\end{array}$ & $\begin{array}{c}\text { Cor do } \\
\text { indicador }\end{array}$ \\
\hline \multirow[t]{3}{*}{$\begin{array}{l}\text { 6. Sistemas de } \\
\text { Informação }\end{array}$} & \multirow[t]{3}{*}{$\begin{array}{l}\text { Existência de sistemas } \\
\text { de informação para o } \\
\text { desenvolvimento das } \\
\text { atividades }\end{array}$} & \multirow[t]{3}{*}{10} & $\begin{array}{l}\mathrm{O}(\mathrm{s}) \text { sistema(s) informatizado } \\
\text { abrange }(\mathrm{m}) \text { todas as atividades: } \\
\text { logísticas, cadastro de demandas de } \\
\text { pacientes e gerenciais, exceto clínicas }\end{array}$ & \multirow[t]{3}{*}{5,0} & \multirow[t]{3}{*}{ Amarelo } \\
\hline & & & $\begin{array}{l}\mathrm{O}(\mathrm{s}) \text { sistema }(\mathrm{s}) \text { utilizado }(\mathrm{s}) \text { para } \\
\text { registro das atividades do CEAF } \\
\text { alimenta }(\mathrm{m}) \text { a base de dados } \\
\text { nacional }\end{array}$ & & \\
\hline & & & $\begin{array}{l}\mathrm{O}(\mathrm{s}) \text { sistema(s) não interopera }(\mathrm{m}) \\
\text { com outros sistemas do âmbito } \\
\text { municipal (ex. prescrição, } \\
\text { prontuário, dispensação do CBAF) }\end{array}$ & & \\
\hline 7. RH & $\begin{array}{l}\text { Disponibilidade de } \\
\text { RH e preocupação } \\
\text { com a capacitação } \\
\text { contínua }\end{array}$ & 10 & $\begin{array}{l}\text { Realiza capacitações } 2 \text { ou mais vezes } \\
\text { ao ano para farmacêuticos e uma } \\
\text { vez ao ano para profissionais não } \\
\text { farmacêuticos que atuam no CEAF }\end{array}$ & 5,0 & Amarelo \\
\hline \multirow[t]{3}{*}{ 8. Financiamento } & \multirow[t]{3}{*}{$\begin{array}{l}\text { Capacidade de aplicar } \\
\text { as estratégias para } \\
\text { a manutenção do } \\
\text { equilíbrio financeiro } \\
\text { e disponibilidade de } \\
\text { recursos }\end{array}$} & \multirow[t]{3}{*}{10} & $\begin{array}{l}\text { O estado tem planejamento } \\
\text { orçamentário e disponibilidade } \\
\text { financeira capaz de suprir as } \\
\text { necessidades de aquisição para o } \\
\text { CEAF }\end{array}$ & \multirow[t]{3}{*}{10,0} & \multirow[t]{3}{*}{ Verde } \\
\hline & & & $\begin{array}{l}\text { A gestão Estadual do CEAF } \\
\text { apresenta taxa de } 0,21 \% \text { de APAC } \\
\text { glosadas em relação ao total de } \\
\text { APAC geradas pela gestão Estadual } \\
\text { do CEAF no Estado }\end{array}$ & & \\
\hline & & & $\begin{array}{l}\text { A gestão estadual monitora o repasse } \\
\text { de recursos federais, referente } \\
\text { ao grupo } 1 \mathrm{~B} \text {, em relação aos } \\
\text { faturamentos gerados }\end{array}$ & & \\
\hline \multirow[t]{5}{*}{$\begin{array}{l}\text { 9. Programação } \\
\text { / Aquisição de } \\
\text { Medicamentos }\end{array}$} & \multirow[t]{5}{*}{$\begin{array}{l}\text { Existência de } \\
\text { mecanismos } \\
\text { que qualificam } \\
\text { a programação } \\
\text { e a aquisição de } \\
\text { medicamentos }\end{array}$} & \multirow[t]{5}{*}{10} & $\begin{array}{l}\text { Existe instrumento/método } \\
\text { estabelecido para o processo de } \\
\text { programação de medicamentos do } \\
\text { CEAF (de compra centralizada pelo } \\
\text { MS e de compra pela Gestão Estadual) }\end{array}$ & \multirow[t]{5}{*}{10,0} & \multirow[t]{5}{*}{ Verde } \\
\hline & & & $\begin{array}{l}\text { O Estado sempre consegue praticar } \\
\text { as desonerações dos tributos (ICMS) } \\
\text { na aquisição dos medicamentos do } \\
\text { CEAF }\end{array}$ & & \\
\hline & & & $\begin{array}{l}\text { O Estado sempre consegue aplicar o } \\
\text { CAP na aquisição dos medicamentos } \\
\text { do CEAF }\end{array}$ & & \\
\hline & & & $\begin{array}{l}\text { Há mecanismos de punição, } \\
\text { estabelecidos em editais e/ou } \\
\text { contratos, para os fornecedores } \\
\text { que descumprem os critérios } \\
\text { estabelecidos, e sempre são aplicados. }\end{array}$ & & \\
\hline & & & $\begin{array}{l}\text { A gestão estadual desenvolve } \\
\text { estratégias formais e informais para } \\
\text { enfrentar problemas no processo de } \\
\text { aquisição de medicamentos do CEAF }\end{array}$ & & \\
\hline
\end{tabular}


Quadro 1. Resultados da avaliação da capacidade de gestão do Componente Especializado da Assistência Farmacêutica do Estado de São Paulo, por indicador e dimensão.

\begin{tabular}{|c|c|c|c|c|c|}
\hline Indicadores & $\begin{array}{l}\text { Significado do } \\
\text { Indicador }\end{array}$ & $\begin{array}{c}\text { Pontuação } \\
\text { máxima }\end{array}$ & Resultado da Avaliação & $\begin{array}{l}\text { Pontos } \\
\text { obtidos }\end{array}$ & $\begin{array}{c}\text { Cor do } \\
\text { indicador }\end{array}$ \\
\hline \multirow[t]{4}{*}{$\begin{array}{l}\text { 10. Boas Práticas em } \\
\text { Logística }\end{array}$} & \multirow[t]{4}{*}{$\begin{array}{l}\text { Existência de } \\
\text { mecanismos } \\
\text { que qualificam a } \\
\text { distribuição e o } \\
\text { controle de estoque } \\
\text { dos medicamentos }\end{array}$} & \multirow[t]{4}{*}{10} & $\begin{array}{l}\text { A Gestão Estadual fornece diretrizes } \\
\text { para o Almoxarifado Central visando } \\
\text { às boas práticas de transporte de } \\
\text { medicamentos para as unidades que } \\
\text { desenvolvem atividades do CEAF } \\
\end{array}$ & \multirow[t]{4}{*}{9,0} & \multirow[t]{4}{*}{ Verde } \\
\hline & & & $\begin{array}{l}\text { Existe um cronograma estabelecido } \\
\text { de abastecimento de medicamentos } \\
\text { para as unidades e fluxo extra } \\
\text { cronograma }\end{array}$ & & \\
\hline & & & $\begin{array}{l}\text { Almoxarifado Central realiza } \\
\text { inventário físico periódico }\end{array}$ & & \\
\hline & & & $\begin{array}{l}\text { 94\% das FME realiza inventário } \\
\text { físico periódico }\end{array}$ & & \\
\hline \multirow[t]{4}{*}{$\begin{array}{l}\text { 11. Disponibilidade } \\
\text { de Medicamentos }\end{array}$} & \multirow{4}{*}{$\begin{array}{l}\text { Preocupação com } \\
\text { o atendimento } \\
\text { oportuno dos } \\
\text { usuários }\end{array}$} & \multirow[t]{4}{*}{10} & $\begin{array}{l}37,4 \% \text { dos medicamentos do grupo } \\
\text { 1B e } 2 \text { estiveram em falta por mais } \\
\text { de um mês no último ano }\end{array}$ & \multirow[t]{4}{*}{6,5} & \multirow[t]{4}{*}{ Amarelo } \\
\hline & & & $\begin{array}{l}\text { O Estado prevê estoque estratégico } \\
\text { nas unidades que desenvolvem } \\
\text { atividades de execução do CEAF ou } \\
\text { almoxarifado central }\end{array}$ & & \\
\hline & & & $\begin{array}{l}\text { Não existe avaliação por uma CFT } \\
\text { para seleção de medicamentos do } \\
\text { CEAF por linha de cuidado, visando } \\
\text { a elaboração/atualização do elenco } \\
\text { estadual }\end{array}$ & & \\
\hline & & & $\begin{array}{l}76 \% \text { das FME não detectam atrasos } \\
\text { na dispensação de medicamentos } \\
\text { por falta de RH e/ou deficiências de } \\
\text { infraestrutura para atendimento dos } \\
\text { usuários (havendo disponibilidade } \\
\text { de medicamentos) }\end{array}$ & & \\
\hline \multicolumn{2}{|l|}{ Resultado da Dimensão } & 110 & - & 63,5 & Amarelo \\
\hline
\end{tabular}

racional, 28 na dimensão organizacional e 25 na dimensão sustentabilidade. O tipo de ajuste mais frequente foi o de "Ajuste de escrita para maior clareza e objetividade" ${ }^{24}$.

O número de FME representadas na coleta de dados por Departamento Regional de Saúde (DRS) é apresentada na Figura 3.

Apenas quatro das $37 \mathrm{FME}$ não forneceram os dados, totalizando assim, coleta em 35 unidades (33 FME, uma Direção do CEAF, um Almoxarifado Central). Os resultados da avaliação por indicador e dimensão são apresentados no Quadro 1.

A situação encontrada nas dimensões avaliadas difere em diversos aspectos. A dimensão que atingiu a menor pontuação foi a sustentabilidade, com destaque para os indicadores de controle social, relação entre serviços e aspectos clínicos como os mais críticos. Nesta dimensão, os indicadores melhor avaliados foram o perfil do gestor e acessibilidade.

$\mathrm{Na}$ dimensão organizacional a participação e o acesso descentralizado apresentaram melhor desempenho, enquanto o monitoramento das ações e a regulamentação apareceram como fatores a serem priorizados. Por fim, na dimensão melhor avaliada, a operacional, as principais fortalezas foram aquelas relacionadas às boas práticas em logística, financiamento e programação/ aquisição. As maiores fragilidades se encontraram nas condições normativas e infraestrutura, ou seja, existiam debilidades nas condições legais e sanitárias para o exercício das atividades nas 
Quadro 1. Resultados da avaliação da capacidade de gestão do Componente Especializado da Assistência Farmacêutica do Estado de São Paulo, por indicador e dimensão.

\begin{tabular}{|c|c|c|c|c|c|}
\hline Indicadores & $\begin{array}{l}\text { Significado do } \\
\text { Indicador }\end{array}$ & $\begin{array}{l}\text { Pontuação } \\
\text { máxima }\end{array}$ & Resultado da Avaliação & $\begin{array}{l}\text { Pontos } \\
\text { obtidos }\end{array}$ & $\begin{array}{c}\text { Cor do } \\
\text { indicador }\end{array}$ \\
\hline \multicolumn{6}{|c|}{ Dimensão Sustentabilidade } \\
\hline 1. Controle Social & $\begin{array}{l}\text { Inclusão do CEAF } \\
\text { nas pautas do CES }\end{array}$ & 10 & $\begin{array}{l}\text { No último ano, questões relativas ao } \\
\text { CEAF não foram pautadas junto ao } \\
\text { CES. A equipe compareceu no CES } \\
\text { apenas para esclarecimentos }\end{array}$ & 0,0 & Vermelho \\
\hline \multirow[t]{2}{*}{ 2. Perfil do Gestor } & \multirow{2}{*}{$\begin{array}{l}\text { Condição de } \\
\text { existência do cargo } \\
\text { de coordenador } \\
\text { da assistência } \\
\text { farmacêutica, } \\
\text { formalmente } \\
\text { instituído, } \\
\text { responsável pela } \\
\text { gestão do CEAF e a } \\
\text { qualificação do gestor }\end{array}$} & \multirow[t]{2}{*}{10} & $\begin{array}{l}\text { Existe o cargo de coordenador/ } \\
\text { diretor/gerente da AF } \\
\text { formalmente instituído porém, } \\
\text { este não é responsável pela gestão } \\
\text { integral do CEAF (técnica e } \\
\text { administrativamente) }\end{array}$ & \multirow[t]{2}{*}{7,5} & \multirow[t]{2}{*}{ Verde } \\
\hline & & & $\begin{array}{l}\text { O coordenador/diretor/gerente da } \\
\text { AF tem formação na área de gestão e } \\
\text { experiência em AF }\end{array}$ & & \\
\hline \multirow[t]{3}{*}{3 Acessibilidade } & \multirow{3}{*}{$\begin{array}{l}\text { Prazo para } \\
\text { atendimento dos } \\
\text { usuários, existência } \\
\text { de demanda judicial e } \\
\text { de mecanismos para } \\
\text { evitar as ações }\end{array}$} & \multirow[t]{3}{*}{10} & $\begin{array}{l}\text { Apenas } 3,5 \% \text { dos pacientes que } \\
\text { buscaram o programa AcessaSUS } \\
\text { no último ano, eram elegíveis ao } \\
\text { CEAF }\end{array}$ & \multirow[t]{3}{*}{9,0} & \multirow[t]{3}{*}{ Verde } \\
\hline & & & $\begin{array}{l}\text { Em média, o tempo decorrido entre } \\
\text { abertura do processo até a primeira } \\
\text { dispensação das } 10 \text { doenças mais } \\
\text { frequentes no estado é de } 6 \text { a } 20 \text { dias }\end{array}$ & & \\
\hline & & & $\begin{array}{l}\text { 91\% dos pacientes cadastrados no } \\
\text { último ano foram atendidos }\end{array}$ & & \\
\hline \multirow[t]{2}{*}{$\begin{array}{l}\text { 4. Relações entre } \\
\text { serviços }\end{array}$} & \multirow[t]{2}{*}{$\begin{array}{l}\text { Ações de } \\
\text { acompanhamento } \\
\text { das unidades; } \\
\text { repasse periódico de } \\
\text { orientações e relação } \\
\text { da gestão com os } \\
\text { outros setores da rede } \\
\text { de atenção à saúde }\end{array}$} & \multirow[t]{2}{*}{10} & $\begin{array}{l}\text { Gestor (nível central): considera } \\
\text { que repassa orientações, quanto à } \\
\text { execução do CEAF e realiza ações } \\
\text { de acompanhamento das unidades. } \\
\text { FME: } 91 \% \text { relatam ter recebido } \\
\text { orientações quanto a execução do } \\
\text { CEAF pelo gestor central e apenas } \\
\text { 9\% relatam ter recebido visita técnica } \\
\text { presencial de acompanhamento }\end{array}$ & \multirow[t]{2}{*}{3,5} & \multirow[t]{2}{*}{ Laranja } \\
\hline & & & $\begin{array}{l}\text { A gestão estadual não discute } \\
\text { demandas do CEAF (consultas, } \\
\text { exame, absenteísmo, atenção básica) } \\
\text { com outros serviços da rede de } \\
\text { atenção a saúde }\end{array}$ & & \\
\hline
\end{tabular}

continua

unidades de dispensação dos medicamentos do CEAF.

\section{Discussão}

Este estudo permitiu avaliar da capacidade de gestão do CEAF no ESP. As adaptações realizadas no protocolo desenvolvido por Rover et al. ${ }^{6}$ consideraram o ponderado na literatura ${ }^{11,27}$, sobre a importância da adequação dos indicadores de forma participativa, para que reflitam o contexto local. Além da adaptação à realidade do ESP, as oficinas de consenso possibilitaram ganhos para a AF a partir das discussões geradas durante o processo de trabalho, integrando os profissionais do setor.

A avaliação demostrou que questões relacionadas à dimensão operacional, ou seja, os processos e operações técnicas encontram-se mais 
Quadro 1. Resultados da avaliação da capacidade de gestão do Componente Especializado da Assistência Farmacêutica do Estado de São Paulo, por indicador e dimensão.

\begin{tabular}{|c|c|c|c|c|c|}
\hline Indicadores & $\begin{array}{l}\text { Significado do } \\
\text { Indicador }\end{array}$ & $\begin{array}{l}\text { Pontuação } \\
\text { máxima }\end{array}$ & Resultado da Avaliação & $\begin{array}{l}\text { Pontos } \\
\text { obtidos }\end{array}$ & $\begin{array}{c}\text { Cor do } \\
\text { indicador }\end{array}$ \\
\hline \multirow[t]{2}{*}{ 5. Aspectos Clínicos } & \multirow{2}{*}{$\begin{array}{l}\text { Existência do } \\
\text { monitoramento } \\
\text { dos tratamentos } \\
\text { e a realização } \\
\text { do primeiro } \\
\text { atendimento pelo } \\
\text { farmacêutico }\end{array}$} & \multirow[t]{2}{*}{10} & $\begin{array}{l}\text { Em apenas } 21 \% \text { das unidades a } \\
\text { primeira dispensação (de todos os } \\
\text { medicamentos ou para hepatite C } \\
\text { e outras patologias específicas) ao } \\
\text { paciente é realizado pelo farmacêutico }\end{array}$ & \multirow[t]{2}{*}{0,0} & \multirow[t]{2}{*}{ Vermelho } \\
\hline & & & $\begin{array}{l}\text { 0,7\% dos aspectos clínicos tratados } \\
\text { nos PCDT estão registrados em } \\
\text { sistema informatizado }\end{array}$ & & \\
\hline \multirow[t]{3}{*}{$\begin{array}{l}\text { 6. Relação com os } \\
\text { usuários }\end{array}$} & \multirow{3}{*}{\begin{tabular}{|l|} 
Preocupação \\
da gestão com \\
a satisfação dos \\
usuários, através de \\
avaliações e ouvidoria
\end{tabular}} & 10 & $\begin{array}{l}\text { 30\% das FME realizaram pesquisa } \\
\text { de satisfação com usuário no último } \\
\text { ano }\end{array}$ & \multirow[t]{3}{*}{3,8} & \multirow[t]{3}{*}{ Laranja } \\
\hline & & & $\begin{array}{l}27 \% \text { das FME utilizam dados } \\
\text { registrados na pesquisa de satisfação } \\
\text { para aprimorar seus processos de } \\
\text { trabalho }\end{array}$ & & \\
\hline & & & $\begin{array}{l}\text { Há ouvidoria que permita } \\
\text { manifestação do paciente quanto aos } \\
\text { serviços prestados pela gestão estadual } \\
\text { do CEAF, porém, a gestão não utiliza } \\
\text { os dados obtidos pela ouvidoria para } \\
\text { questões de planejamento }\end{array}$ & & \\
\hline \multicolumn{2}{|c|}{ Resultado da Dimensão } & 60 & - & 23,8 & Laranja \\
\hline \multicolumn{2}{|c|}{ Pontuação total do Protocolo } & 250 & - & 125 & - \\
\hline
\end{tabular}

Fonte: Elaborado pelas autoras.

Legenda: CES: Conselho Estadual de Saúde; CIB: Comissão Intergestores Bipartite; CEAF: Componente Especializado da Assistência Farmacêutica; AF: Assistência Farmacêutica; PES: Plano Estadual de Saúde; PPA: Programação Plurianual; RH: Recursos Humanos; SR: Serviço de Referência; APAC: Autorização de Procedimento de Alto Custo; PGRSS: Programa de Gerenciamento de Resíduos de Serviços de Saúde; CFT: Comissão de Farmácia e Terapêutica; CBAF: Componente Básico da Assistência Farmacêutica; PCDT: Protocolos Clínicos e Diretrizes Terapêuticas; CRF: Conselho Regional de Farmácia; FME: Farmácias de Medicamentos Especializados; ICMS: Imposto sobre Operações relativas à Circulação de Mercadorias e Prestação de Serviços de Transporte Interestadual e Intermunicipal e de Comunicação; CAP: Coeficiente de Adequação de Preços.

1.Grupo 1B: medicamentos financiados pelo Ministério da Saúde mediante transferência de recursos financeiros para aquisição pelas Secretarias de Saúde dos Estados e Distrito Federal sendo delas a responsabilidade pela programação, armazenamento, distribuição e dispensação para tratamento das doenças contempladas no âmbito do Componente Especializado da Assistência Farmacêutica; Grupo 2: medicamentos sob responsabilidade das Secretarias de Saúde dos Estados e do Distrito Federal pelo financiamento, aquisição, programação, armazenamento, distribuição e dispensação para tratamento das doenças contempladas no âmbito do Componente Especializado da Assistência Farmacêutica. 2. A execução do Componente Especializado da Assistência Farmacêutica envolve as etapas de solicitação, avaliação, autorização, dispensação e renovação da continuidade do tratamento ${ }^{1}{ }^{3}$. Programa do ESP que visa triar a necessidade dos pacientes que ainda não encontraram o acesso aos seus medicamentos no SUS, bem como recebe demandas administrativas via Ministério Público e Defensoria Pública antes de entrarem com Ação Judicial ${ }^{26}$.

bem desenvolvidas e estruturadas. Este resultado, já encontrado em outros estudos ${ }^{6,9,12}$ demonstra o forte desenvolvimento técnico da $\mathrm{AF}$ ao longo das últimas décadas. A partir do início dos anos 2000, a descentralização das ações e do financiamento da AF exigiu definições teórico-metodológicas e o desenvolvimento de serviços nas secretarias de saúde ${ }^{28}$. Assim, aspectos operacionais, como financiamento, programação/aquisição e boas práticas em logística foram avaliados como “de acordo". Estes são aspectos bastante normatizados e definidos nacionalmente para estados e municípios (no que cabe a cada ente federado) e, portanto, mais objetivos no sentido de haver procedimentos e regras bem estabelecidas para sua execução. Cabe ressaltar a importância de a gestão estadual manter e aperfeiçoar estes indicadores, os quais são essenciais para a qualidade dos medicamentos e, principalmente, para a garantia do acesso aos pacientes e sua segurança ${ }^{29}$.

Em relação ao financiamento, os resultados positivos são relacionados aos planejamentos orçamentários anuais e à disponibilidade financeira capaz de suprir as necessidades de aquisição. 
Quadro 2. Critérios de julgamentos dos indicadores e dimensões, considerando as faixas de pontuação dos indicadores, a escala de cores e o seu significado.

\begin{tabular}{|c|c|c|c|}
\hline $\begin{array}{l}\text { Critérios de } \\
\text { julgamentos }\end{array}$ & Cor & Pontuação & $\mathrm{O}$ que indica \\
\hline \multirow[t]{4}{*}{ Indicadores } & Verde & 75 a $100 \%$ dos pontos & $\begin{array}{l}\text { Manter/Avançar - representa os indicadores que estão de } \\
\text { acordo com a os parâmetros considerados aceitáveis pelos } \\
\text { especialistas }\end{array}$ \\
\hline & Amarelo & 50 a $74 \%$ dos pontos & $\begin{array}{l}\text { Cuidado - sinaliza os indicadores que apresentaram avanços, } \\
\text { porém precisam ser aperfeiçoados }\end{array}$ \\
\hline & Laranja & 25 a $49 \%$ dos pontos & Alerta - evidencia os indicadores que precisam melhorar \\
\hline & Vermelho & 0 a $24 \%$ dos pontos & $\begin{array}{l}\text { Urgente - sinaliza os indicadores que precisam ser } \\
\text { priorizados }\end{array}$ \\
\hline \multirow[t]{4}{*}{ Dimensões } & Verde & 75 a $100 \%$ dos pontos & $\begin{array}{l}\text { Que a situação encontrada na dimensão vai de acordo com o } \\
\text { preconizado para a capacidade de gestão do CEAF }\end{array}$ \\
\hline & Amarelo & 50 a $74 \%$ dos pontos & $\begin{array}{l}\text { Que há avanços na situação encontrada, mas é preciso o } \\
\text { aprimoramento da capacidade de gestão }\end{array}$ \\
\hline & Laranja & 25 a $49 \%$ dos pontos & Que é preciso melhorar a capacidade de gestão \\
\hline & Vermelho & 0 a $24 \%$ dos pontos & $\begin{array}{l}\text { Que a situação encontrada é crítica e compromete a } \\
\text { capacidade de gestão do CEAF, sinalizando uma prioridade } \\
\text { para a gestão }\end{array}$ \\
\hline
\end{tabular}

Fonte: Adaptado de Rover MRM et al..$^{23}$.

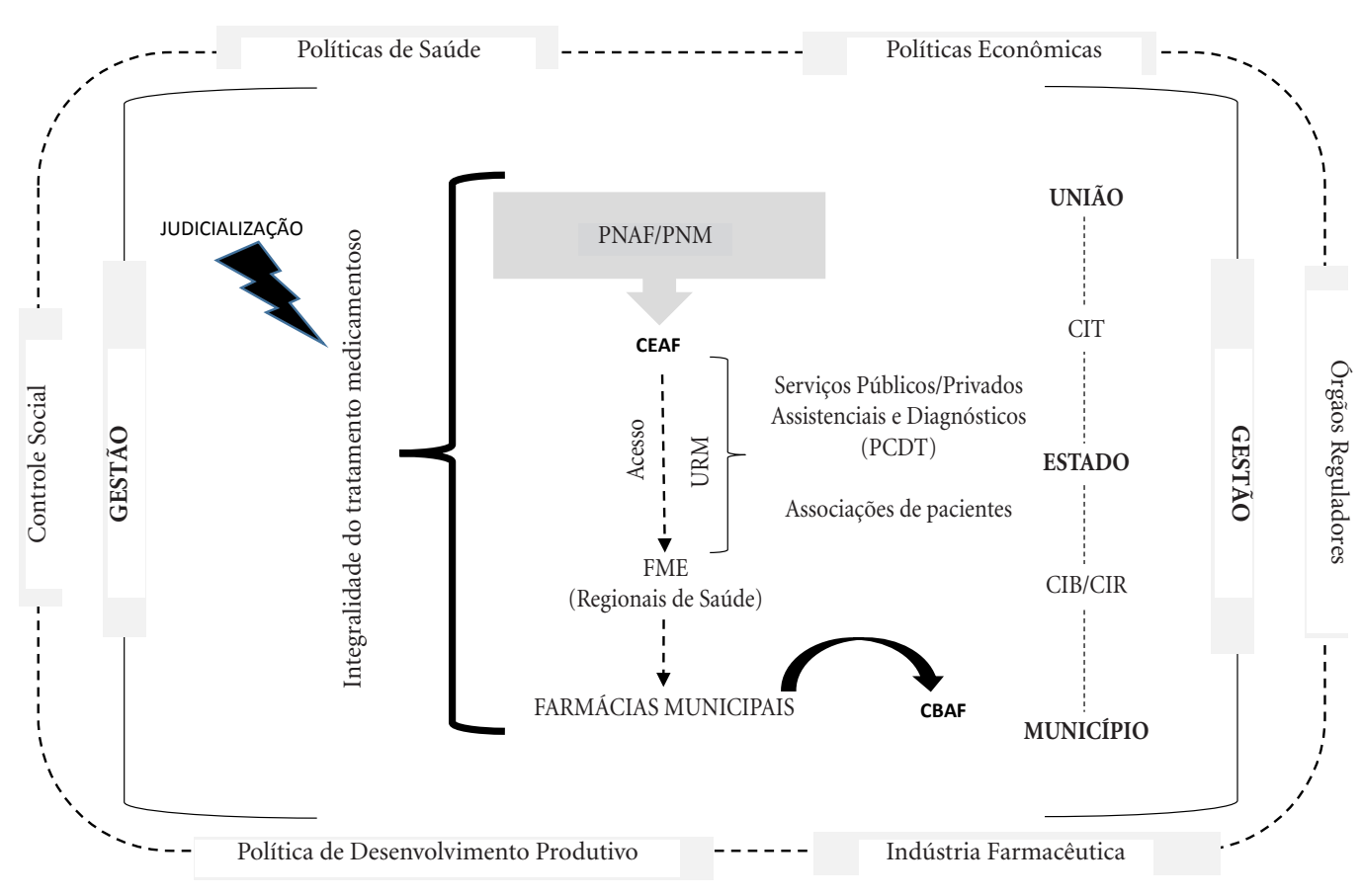

Legenda: CBAF - Componente Básico da Assistência Farmacêutica; CEAF - Componente Especializado da Assistência Farmacêutica; CIB - Comissão Intergestores Bipartite; CIR - Comissão Intergestores Regionais; CIT - Comissão Intergestores Tripartite; FME - Farmácia de Medicamentos Especializados; PNAF - Política Nacional de Assistência Farmacêutica; PNM Política Nacional de Medicamentos; URM - Uso Racional de Medicamentos.

Figura 2. Modelo Teórico: capacidade de gestão do Componente Especializado da Assistência Farmacêutica no ESP. 


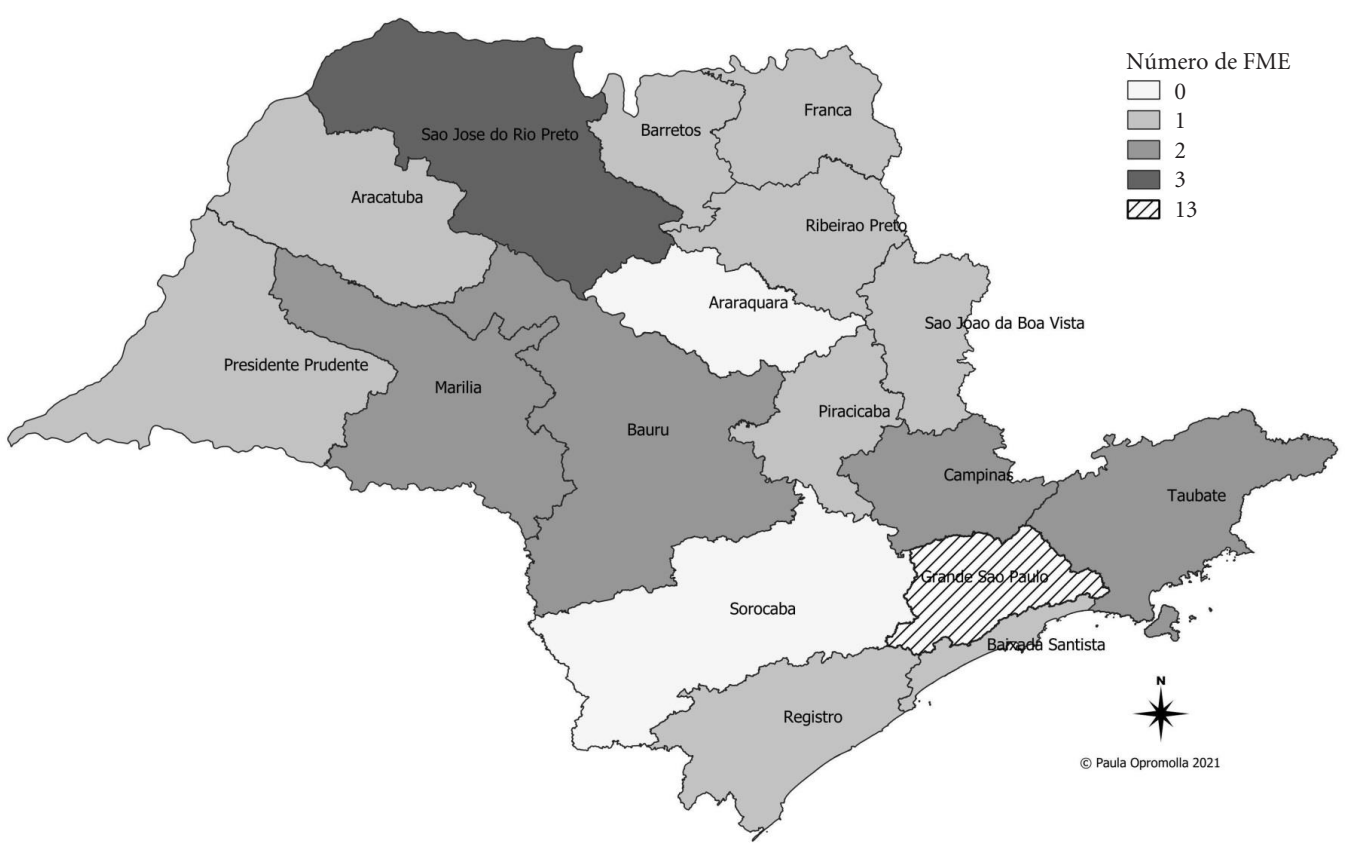

Figura 3. Número de Farmácias de Medicamentos Especializados representadas na coleta de dados para avaliação da capacidade de gestão do Componente Especializado da Assistência Farmacêutica no Estado de São Paulo por Departamento Regional de Saúde.

Fonte: Elaborado pelas autoras.

Destacaram-se, ainda, as glosas inferiores a $0,3 \%$ e o monitoramento dos repasses nacionais fundo -a-fundo. Porém, foi apontado pelo gestor estadual que as demandas judiciais e administrativas acabam deslocando recursos e comprometendo este equilíbrio, o que pode vir a afetar a disponibilidade financeira. Segundo Medeiros ${ }^{30}$, do total gasto com saúde no ESP, 9,86\% foi destinado à aquisição de medicamentos e as leis orçamentárias anuais contemplaram recursos para aquisição, produção e distribuição de medicamentos.

Considerando que a programação de medicamentos é fundamental para garantir sua disponibilidade em quantidade e prazo adequados às necessidades dos usuários, bem como evitar o desperdício (p. 14), é importante que a SES/SP mantenha e aperfeiçoe os métodos utilizados ${ }^{31}$. Quanto à aquisição de medicamentos, a SES/SP, assim como a Secretaria da Saúde do Estado de Santa Catarina (ESC) ${ }^{6}$ tem conseguido propostas vantajosas para a Administração Pública ao aplicar Coeficiente de Adequação de Preço (CAP) e desonerações de tributos nas compras de medicamentos do CEAF. Além disso, possuía estratégias formais e informais para o enfrentamento de problemas no processo de aquisição, como por exemplo, o registro de preços.

Embora a SES/SP formalize o faturamento dos medicamentos (como por exemplo, atorvastatina, fenoterol e ciclosporina) que integram o grupo 2 do CEAF, evidenciando a sua participação no financiamento do componente e respeitando as linhas de cuidado estabelecidas pelos PCDT, ainda precisa aperfeiçoar a capacidade de execução quanto à complementariedade, pois, até o momento, não existe pactuação de elenco mínimo junto aos municípios no âmbito da CIB para atendimento da primeira linha de cuidado (grupo 3). Este indicador relaciona-se, também, as fragilidades identificadas de comunicação com os municípios. Vale ressaltar que o Grupo 3 trata de medicamentos sob responsabilidade das Secretarias de Saúde do Distrito Federal e dos Municípios para aquisição, programação, armazenamento, distribuição e dispensação e que está estabelecida em ato normativo específico que regulamenta o Componente Básico da Assistência Farmacêutica. A organização da AF por componentes, com regras e financiamento distintos, aumenta o desafio dos gestores em viabilizar 
o acesso aos medicamentos de forma integral. Desta forma, é de extrema importância a busca de mecanismos que visam essa integralidade, a exemplo do ESC onde existe um elenco mínimo do grupo 3 pactuado em $\mathrm{CIB}^{6,32}$.

Nesta dimensão, dois indicadores - condições normativas e infraestrutura - não alcançaram os parâmetros estipulados, necessitando ser priorizados pelo gestor. Apesar dos investimentos na infraestrutura das farmácias, na informatização da rede no período de 2013 a 2016, e do desenvolvimento de iniciativas voltadas à ampliação da capacidade de armazenamento no almoxarifado central da $\mathrm{SES}^{30}$, os dados coletados indicam a necessidade de maior investimento nas unidades que dispensam os medicamentos. A adequação da infraestrutura para atendimento das normas sanitárias visa ampliar a qualidade dos serviços, assegurar a qualidade dos medicamentos e segurança dos pacientes. É importante destacar que tanto as unidades de gestão direta quanto de gestão indireta (por OSS) apresentaram debilidades de infraestrutura. Assim, apesar das unidades gerenciadas por OSS receberem repasses financeiros para investimento nas unidades, as dificuldades de infraestrutura identificadas chamam a atenção para a necessidade crescente de avaliação dos contratos público-privados ${ }^{33}$.

Ao avaliar a capacidade de gestão, em relação à dimensão organizacional, identifica-se que os indicadores monitoramento e avaliação das ações, e regulamentação precisam ser priorizados pela gestão estadual. Estes indicaram deficiências de estratégias claras de avaliação permanente dos serviços e da política pública, que permitam tomar decisões em tempo real, a partir de evidências. Sabe-se, contudo, que a prática da avaliação no SUS ainda não está plenamente instituciona$\operatorname{lizada}^{34}$. Quanto à regulamentação, no momento da avaliação, existia procedimento regulamentado apenas para a etapa de solicitação e renovação da continuidade do tratamento. Faz-se necessária a construção de um manual de boas práticas que formalize e harmonize as ações da equipe central e regionais quanto às etapas de avaliação, autorização e dispensação. Para Rover ${ }^{32}$, as regulamentações são o primeiro passo para desenvolvimento de atividades institucionalizadas e demonstram o grau de interesse e o compromisso com o estabelecimento de fluxos e normas que legitimem e viabilizem a organização das atividades do CEAF.

Ainda, até o momento da avaliação, não havia no ESP a divulgação, de fácil acesso para toda a população, da lista de medicamentos em falta e o motivo. Durante a coleta de dados, os gestores informaram que enviavam semanalmente às FME $e$ municípios estas informações, porém, que estas não eram divulgadas diretamente à população. Assim, para aperfeiçoar o fluxo de informações e dar maior transparência a gestão do CEAF, está em construção um portal on-line para que o paciente possa buscar de forma individual a informação de abastecimento de seus medicamentos e respectivas justificativas em caso de faltas.

Nesta dimensão, apenas os indicadores participação e acesso descentralizado destacaramse positivamente com resultados que devem ser mantidos e aperfeiçoados. Observou-se que a gestão teve participação em várias instâncias formais (CIB, CES, reuniões para a elaboração do PES), porém, possui deficiências em envolver os participantes do CEAF (pacientes, prescritores, entre outros) na formulação de políticas e diretrizes deste componente. Assim, ressalta-se a necessidade de criação de novas estratégias que fomentem a construção de políticas de forma mais participativa e transparente. Quanto ao acesso descentralizado, a SES/SP destaca-se por capilarizar o acesso aos medicamentos do CEAF para 95\% dos municípios, por FME ou farmácias municipais. O ESP é a terceira unidade administrativa mais populosa da América do Sul ${ }^{13}$, assim, a descentralização é essencial para facilitar o acesso dos pacientes aos medicamentos e permitir a organização dos serviços às realidades locais. Entretanto, segundo Medeiros ${ }^{30}$, ainda é heterogênea a proporção entre a população atendida pelas FME e a população abrangida por região do DRS, variando de 0,4 (DRS 11 - Presidente Prudente) a 10,1 (DRS 4 - Baixada Santista), ou seja, por mais que existam locais de acesso na maioria dos municípios, ainda assim existem proporções diferentes de acesso nas regiões.

Dos seis indicadores avaliados na dimensão sustentabilidade, apenas o perfil do gestor e acessibilidade atingiram os parâmetros esperados. Para as dez doenças mais frequentes no estado, em média de 6 a 20 dias foi o tempo decorrido entre a solicitação do medicamento e a primeira dispensação. Em estudo semelhante realizado no ESC, este tempo foi de 50 dias $^{32}$. Possivelmente, a diferença de dias se deve ao fato de que no ESC a avaliação e autorização das solicitações ocorrem de forma centralizada, enquanto que no ESP a avaliação e autorização são realizadas na própria unidade de dispensação, sendo atribuído a este tempo de espera o prazo para a distribuição de medicamentos, das unidades estaduais (FME) para as unidades municipais da região. 
Sabe-se que a demora para atendimento é uma das causas de demanda judicial destes medicamentos $^{35}$. No estado de Minas Gerais, somente entre as etapas de registro dos documentos de solicitação de medicamentos de Alzheimer (em nível regional) até o seu retorno com o parecer do analista (em nível central), o tempo médio variou de 20 a 87 dias. Assim, os autores concluem sobre a importância de o gestor ter um maior controle sobre o trâmite administrativo, para que este seja mais rápido e menos burocrático ${ }^{35}(\mathrm{p} .11)$.

Ainda cabe destacar que a acessibilidade aos medicamentos do CEAF é dependente do acesso à rede de atenção à saúde, ou seja, depende do diagnóstico, de exames específicos, de consultas com especialistas, por exemplo. Esta questão, somada as necessidades e realidades locais, precisa ser considerada desde a incorporação dos medicamentos, visando o fortalecimento e a democratização das políticas envolvidas ${ }^{9,36}$. Estes achados evidenciam a necessidade de criação de fluxos mais ágeis, visando o atendimento oportuno dos usuários, o que redundará na sustentabilidade da gestão pela satisfação das necessidades dos pacientes e possível redução da judicialização ${ }^{37}$.

Apenas 30\% das unidades que dispensam medicamentos do CEAF pesquisadas realizaram pesquisa de satisfação junto aos usuários. Além disso, os dados obtidos pela ouvidoria não eram utilizados no planejamento das ações. Assim, fica evidente a necessidade de aperfeiçoamento da relação com usuários e utilização de informações provenientes desta relação para o planejamento e aprimoramento dos serviços. Estes resultados revelam a necessidade de aproximar a gestão e a "ponta", e que o gestor estabeleça canais de comunicação eficientes, de modo que facilitem a identificação e a solução das barreiras, de oportunidades, criando um ambiente favorável para sustentar as decisões ${ }^{6,38}$

Por fim, ainda nesta dimensão, dois indicadores precisam ser priorizados pela gestão, pois ambos - controle social e aspectos clínicos - não receberam nenhuma pontuação na avaliação, indicando o caráter de urgência. O indicador de controle social evidenciou que, no ano anterior, questões relativas ao CEAF não foram pautadas junto ao Conselho Estadual de Saúde (CES), sendo que todas as vezes que a equipe compareceu nas reuniões foi apenas para prestar esclarecimentos. É de fundamental importância que questões do CEAF sejam compartilhadas nesta instância, uma vez que, estratégias acordadas neste âmbito serão monitoradas por seus representantes. É também junto ao CES que os gestores podem compreender as demandas, apresentar os projetos e buscar apoio social e político, conferindo sustentabilidade, e contribuindo para a ampliação da capacidade de gestão $0^{30,39}$.

Em relação aos aspectos clínicos, foi evidenciado que apenas $0,7 \%$ dos usuários tinham registro de monitoramento dos tratamentos em sistema informatizado da SES/SP. Portanto, havia pouca capacidade de avaliação e de acompanhamento de informações clínico-assistenciais e dos impactos do CEAF nos resultados em saúde. Fato que poderá colaborar para o aperfeiçoamento deste aspecto foi o lançamento do Programa de Cuidados Farmacêuticos pelo MS, no início de 2018. Este projeto visa ao acompanhamento dos tratamentos (inicialmente) dos pacientes com hepatite e artrite reumatoide, por meio de consultas farmacêuticas, os quais deverão ser registrados para a continuidade do cuidado ${ }^{40}$.

Cabe destacar que a metodologia adotada na pesquisa não teve como propósito concluir se a capacidade de gestão do ESP é "boa" ou "ruim", mas, sim, analisá-la como processo que se encontra em diferentes estágios de evolução, na perspectiva de apontar para o aprimoramento do processo, ou seja, quais pontos podem ser corrigidos, quais investimentos são necessários e com qual urgência ${ }^{11}$.

Como alternativas aos problemas identificados, sugere-se a realização do planejamento de ações que aprimorem a gestão do CEAF, tornando -o ferramenta gerencial que facilite o delineamento, monitoramento e avaliação das metas estabelecidas $^{41-43}$. Neste caso, pode-se partir da construção de planos de ação para a superação de obstáculos evidenciados nos indicadores com piores resultados.

Há a necessidade da formalização das relações entre as farmácias que realizam as etapas de execução do componente, e de suas relações com outros serviços de saúde ${ }^{6}$. Considerando que a Comissão Intergestores Regionais é o foro interfederativo para negociação e pactuação, de planejamento regional, de ações, serviços e elenco de medicamentos, é de extrema importância que o gestor estadual do CEAF crie ou reforce as estratégias de representação nesta instância, atuando ativamente de pautas que propiciem discussões de demandas do componente com outros gestores $^{44}$. São também necessários o planejamento e a previsão de recursos nos instrumentos de gestão do SUS, para o aprimoramento da infraestrutura das unidades que executam atividades do CEAF, o que facilitará o atendimento aos requisitos sanitários e legais e contribuirá para a qualidade dos serviços prestados ${ }^{3,45}$. 
O aperfeiçoamento da capacidade de identificar junto ao usuário suas necessidades criando mecanismos para que estas informações subsidiem as estratégias de atuação do gestor, bem como a maior participação social na formulação de políticas do componente no Estado são fundamentais ${ }^{9,42,46}$. Por fim, há a necessidade de priorizar os aspectos clínicos, direcionando farmacêuticos também para questões assistenciais, aperfeiçoando as ações de cuidado farmacêutico no $\mathrm{CEAF}^{6}$. Para a superação desta limitação são necessárias medidas como o desenvolvimento de atividades de capacitação focadas nas questões organizacionais e funcionais das farmácias, comprometendo o profissional farmacêutico em um nível maior de responsabilidade ${ }^{38}$.

A coleta de informações desta pesquisa não incluiu as farmácias municipais, pois estas não participam de todas as atividades de execução do CEAF, e as atividades que executam não estão formalmente pactuadas no Estado. Porém, farmacêuticos atuantes na AF municipal foram incluídos nas etapas de validação, deste estudo, de forma que o instrumento de avaliação esteja validado também para aplicação neste âmbito, podendo a SES/SP contemplar, quando viável, as farmácias municipais. Este estudo apresenta ainda como limitação a utilização de dados referidos pelos informantes, pois as unidades não possuem, ou não disponibilizam publicamente, todos os dados relativos à organização e gestão do componente.

\section{Considerações finais}

Este estudo apresenta a aplicação de indicadores para a avaliação da capacidade de gestão do CEAF levando em consideração as especificidades da organização da AF no estado. Considerando a importância do tema no contexto nacional, o estudo aqui apresentado provê informações importantes para viabilizar e estimular os processos regulares de avaliação e monitoramento da assistência farmacêutica em todos os âmbitos, contribuindo para o melhor acesso e uso racional de medicamentos e recursos da saúde.

A avaliação final, neste estado, expressa a necessidade de investimentos na qualificação da gestão do CEAF em todas as dimensões, mas especialmente na dimensão de sustentabilidade. Avanços são fundamentais para a garantia da integralidade dos tratamentos medicamentosos e melhores resultados de saúde da população.
Para tanto, há a necessidade de ações claras e pactuadas, planejamento e avaliação que direcionem para o alcance e manutenção dos recursos operacionais, técnicos e humanos visando o atendimento oportuno, integral e contínuo. Os problemas de infraestrutura, a ausência de serviços de farmacêuticos para a promoção da melhor utilização dos medicamentos e os problemas de articulação da gestão com usuários, profissionais e outros setores da administração pública são fatores capacitantes que restringem o acesso, os resultados terapêuticos pretendidos, além de constrangerem a sustentabilidade do próprio projeto de gestão.

Cabe ressaltar as condições favoráveis da gestão do CEAF no ESP e que precisam ser mantidas: a sua participação ativa em instâncias colegiadas do SUS; a alta capilarização da dispensação de medicamentos; a eficiente gestão do financiamento; a existência de métodos bem estabelecidos de programação e aquisição; avanços no atendimento de boas práticas na logística; e a existência do cargo de gestor da AF.

Este estudo traz subsídios para a qualificação da gestão e acesso aos medicamentos de alto preço no SUS, para a tomada de decisão do gestor, e a melhoria contínua dos serviços. Considerando a importância do CEAF na AF, por abranger os medicamentos de maior preço e viabilizar o acesso aos medicamentos recentemente incorporados no SUS, além da complexidade da gestão e das doenças envolvidas, faz-se necessário o aprimoramento contínuo dos mecanismos de gestão, da qual a avaliação é etapa fundamental.

\section{Colaboradores}

Os autores participaram igualmente de todas as etapas de elaboração do artigo.

\section{Financiamento}

A pesquisa foi financiada pelo Departamento de Ciência e Tecnologia/SCTIE do Ministério da Saúde, por intermédio do $\mathrm{CNPq}$, com o apoio da Fundação de Amparo à Pesquisa do Estado de Santa Catarina (FAPESC). 


\section{Referências}

1. Brasil. Ministério da Saúde (MS). Portaria de Consolidação $n^{\circ} 2$, de 28 de setembro de 2017: Consolidação das normas sobre as políticas nacionais de saúde do Sistema Único de Saúde. Brasília: MS; 2017. [acessado 2018 fev 5]. Disponível em: http://bvsms.saude.gov.br/bvs/ saudelegis/gm/2017/prc0002_03_10_2017.html

2. Brasil. Ministério da Saúde (MS).Da excepcionalidade às linhas de cuidado: o Componente Especializado da Assistência Farmacêutica. Brasília: MS; 2010.

3. Brasil. Conselho Nacional de Secretários de Saúde (CONASS). Assistência farmacêutica no SUS: para entender a gestão do SUS. Brasília: CONASS; 2011.

4. São Paulo (Estado). Secretaria da Saúde, Conselho de Secretários Municipais de Saúde (COSEMS) - São Paulo. Assistência farmacêutica no SUS: SUS no Estado de São Paulo: atualização para gestores municipais. São Paulo: SES/SP e COSEMS/SP; 2013.

5. Machline C. A Assistência à Saúde no Brasil. In: Storpirtis S, Mori ALPM, Yochiy A, Ribeiro E, Porta V. Farmácia Clínica e Atenção Farmacêutica. Rio de Janeiro: Guanabara-Koogan; 2008.

6. Rover MRM, Vargas-Peláez CM, Faraco EB, Farias MR, Leite SN. Avaliação da capacidade de gestão do componente especializado da assistência farmacêutica. Cien Saude Colet 2017; 22(8):2487-2499.

7. Lugones R, Bermudez JAZ, Bonfim JRA. Analisis comparado de politica de medicamentos. São Paulo: Hucitec/Sobravime; 1999.

8. Barreto JL. Análise da gestão descentralizada da assistência farmacêutica: um estudo em municípios baianos [dissertação]. Salvador: Universidade Federal da Bahia; 2007.

9. Barreto JL, Guimarães MCL. Evaluation of decentralized management of basic pharmaceutical care in Bahia State, Brazil. Cad Saude Publica 2010; 26(6):1207-1220.

10. Matus C. Política, planejamento e governo. Brasília: Instituto de Pesquisa Econômica Aplicada; 1993.

11. Guimaraes MCL, Santos SMC, Melo C, Sanches Filho A. Avaliação da capacidade de gestão de organizações sociais: uma proposta metodológica em desenvolvimento. Cad Saude Publica 2004; 20(6):1642-1650.

12. Mendes SJ, Leite SN. Resultados gerais da avaliação da gestão da assistência farmacêutica em Santa Catarina. In: LEITE SN, Farias MR, Manzini F, Mendes SJ, Rover MRM. Gestão da Assistência Farmacêutica: Proposta para Avaliação no Contexto Municipal: A Experiência em Santa Catarina. Florianópolis: Editora da UFSC; 2015. p. 147-164.

13. São Paulo (Estado). Secretaria da Saúde. Diagnóstico PES 2020-2023 [acessado 2020 abr 20]. Disponível em: http://www.cosemssp.org.br/wp-content/ uploads/2020/01/PLANO-ESTADUAL-DE-SAUDE-2020-2023.pdf

14. São Paulo (Estado). Secretaria da Saúde. Relatório de Gestão: 3o quadrimestre de 2015. São Paulo: SES/SP; 2015.

15. São Paulo (Estado). Secretaria de Planejamento e Desenvolvimento Regional. Orçamento do Estado 2015: Orçamentos Fiscal, da Seguridade Social e de Investimentos das Empresas. São Paulo: SES/SP; 2015.
16. Martins KOF. Componente Especializado da Assistência Farmacêutica. Apresentação realizada no Grupo Técnico de Assistência Farmacêutica da Comissão Intergestores Bipartite. São Paulo: SES/SP; 2015.

17. Rover MRM, Vargas-Pelaez CM, Fernanda M, Mendes SJ, Farias MR, Leite SN. Modelo Teórico e Lógico para a avaliação da capacidade de gestão do Componente Especializado da Assistência Farmacêutica. Gestão \& Saúde 2016; 7(1):191-210.

18. Rover MRM, Vargas-Peláez CM, Farias MR, Leite SN. Metodologia para o desenvolvimento de um protocolo de indicadores para a avaliação da capacidade de gestão da assistência farmacêutica. UFSC - Especialização em Gestão da Assistência Farmacêutica. Universidade Aberta do SUS (UNASUS). [acessado 2017 jan 5]. Disponível em: https://ares.unasus.gov.br/acervo/ handle/ARES/6141

19. Santos SMC, Guimarães MCL, Melo CMM, Sanches Filho A. Subsídios para avaliação da gestão pública: processo de construção de indicadores para avaliação da capacidade de gestão de organizações sociais. $O \ll S$ 2006; 13(37):109-124.

20. Pringle M, Wilson T, Grol R. Measuring "goodness" in individuals and healthcare systems. BMJ 2002; 325:704-707.

21. Rede Interagencial de Informação para a Saúde (RIP$\mathrm{SA})$. Indicadores básicos para a saúde no Brasil: conceitos e aplicações. 2a ed. Brasília: Organização Pan -Americana da Saúde; 2008 [acessado 2017 jan 17]. Disponível em: http://tabnet.datasus.gov.br/tabdata/ livroidb/2ed/indicadores.pdf.

22. Vieira KM, Dalmoro M. Dilemas na Construção de Escalas Tipo Likert: o Número de Itens e a Disposição Influenciam nos Resultados? Revista Gest@o.Org 2013; 6(3):161-174.

23. Rover MRM, Vargas-Peláez CM, Faraco EB, Mendes SJ, Manzini F, Soares L, Storpirtis S, Farias MR, Leite SN. Da construção à aplicação: indicadores para a avaliação da gestão da assistência farmacêutica - a experiência em Santa Catarina. Florianópolis: Escola Nacional dos Farmacêuticos; 2017.

24. Fatel KO. Avaliação da capacidade de gestão do Componente Especializado da Assistência Farmacêutica no Estado de São Paulo [dissertação]. São Paulo: Universidade de São Paulo; 2018. [acessado 2020 out 25]. Disponível em: https://teses.usp.br/teses/disponiveis/9/9139/tde-03102018-162240/publico/Karina_ de_Oliveira_Fatel_Martins_ME_Original.pdf

25. São Paulo (Estado). Secretaria da Saúde. Regionais de Saúde; 2012. [acessado $2016 \mathrm{dez} 12$ ]. Disponível em: http://www.saude.sp.gov.br/ses/institucional/departamentos-regionais-de-saude/regionais-de-saude

26. São Paulo (Estado). Tribunal de Justiça do Estado de São Paulo (TJSP). Acessa SUS' evitará ações desnecessárias para fornecimento de remédios. Notícias Comunicação Social TJSP - CA (texto). [acessado 2018 abr 3]. Disponível em: http://www.tjsp.jus.br/Noticias/ Noticia? codigoNoticia $=38743$ 
27. Manzini F, Farias MR, Elaboração e aplicação do modelo de avaliação da capacidade de gestão da assistência farmacêutica nos municípios catarinenses. In: Leite SN, Farias MR, Manzini F, Mendes SJ, Rover MRM. Gestão da Assistência Farmacêutica: Proposta para Avaliação no Contexto Municipal: A Experiência em Santa Catarina. Florianópolis: Editora da UFSC; 2015. p. 71-94.

28. Marin N. Assistência Farmacêutica para gerentes municipais. Rio de Janeiro: Opas/OMS; 2003.

29. Pinto VB. Armazenamento e distribuição: o medicamento também merece cuidados. OPAS/OMS 2016; 1(12):1-7.

30. Medeiros AL. Assistência farmacêutica no SUS: responsabilidade compartilhada por União, Estados e Municípios. São Paulo/SP [tese]. Faculdade de Saúde Pública da Universidade de São Paulo; 2018.

31. Brasil. Ministério Público Federal. Procuradoria Federal dos Direitos do Cidadão. Guia de referência para o Ministério Público Federal: assistência farmacêutica. Brasília: MPF; 2017. [acessado 2018 jan 20]. Disponível em: http://www.mpf.mp.br/atuacao-tematica/ pfdc/midiateca/nossas-publicacoes/guia-para-o-mpf-assistencia-farmaceutica-2017

32. Rover MRM. Avaliação da capacidade de gestão do Componente Especializado da Assistência Farmacêutica em Santa Catarina [tese]. Universidade Federal de Santa Catarina, Centro de Ciências da Saúde, Programa de Pós-Graduação em Farmácia. Florianópolis: UFSC; 2016.

33. Soares GB, Borges FT, Santos RR, Garbin CAS, Moimaz SAS, Siqueira CEG. Organizações Sociais de Saúde (OSS): Privatização da Gestão de Serviços de Saúde ou Solução Gerencial para o SUS? Gestão e Saúde 2016; $7(2): 828-850$.

34. Tanaka OY, Melo C. Avaliação de Serviços e Programas de Saúde para a Tomada de Decisão. In: Rocha AA; Cesar CLG. Saúde Pública: Bases Conceituais. São Paulo: Atheneu; 2008.

35. Almeida-Brasil CC, Costa JO, Aguiar VCFS, Moreira DP, Moraes EN, Acúrcio FA, Guerra Junior AF, Álvares J. Acesso aos medicamentos para tratamento da doença de Alzheimer fornecidos pelo SUS em Minas Gerais, Brasil. Cad Saude Publica 2016; 2(7):1-14.

36. Dubow C, Borba TT, Santos CR, Garcia EL, Krug SBF. Participação Social na Implementação das Políticas Públicas de Saúde: uma revisão crítico reflexiva. Saude Transf Soc 2017; 8(2):103-111.

37. Rover MRM, Vargas-Peláez CM, Farias MR, Leite SN. Da organização do sistema à fragmentação do cuidado: a percepção de usuários, médicos e farmacêuticos sobre o Componente Especializado da Assistência Farmacêutica em um estado do sul do Brasil. Physis 2016; 26(2):691-711.

38. Lima-Dellamora EC, Caetano R, Osorio-de-Castro CGS. Dispensing specialized component medicines in areas of the State of Rio de Janeiro. Cien Saude Colet 2012; 17(9):2387-2396.
39. Brasil. Ministério da Saúde (MS). Conselhos de saúde: a responsabilidade do controle social democrático do SUS. 2a ed. Brasília: MS; 2013.

40. Brasil. Portal da Saúde. Ministério da Saúde lança Programa de Cuidados Farmacêuticos; 2018. [acessado 2018 abr 18]. Disponível em: http://portalms.saude. gov.br/noticias/agencia-saude/42368-ministerio-dasaude-lanca-programa-de-cuidados-farmaceuticos.

41. Brasil. Ministério da Saúde (MS). Sistema de Planejamento do SUS (PlanejaSUS): uma construção coletiva - trajetória e orientações de operacionalização. Brasília: MS; 2009.

42. Landim ELAS, Guimarães MCL. Gestão da assistência farmacêutica. In: Gestão da Assistência Farmacêutica: Especialização à distância. Universidade Federal de Santa Catarina, Universidade Aberta do SUS. Florianópolis: UFSC; 2011.

43. Gerlack LF, Karnikowski MGA, Areda CA, Galato D, Oliveira AG, Álvares J, Leite SN, Costa EA, Guibu IA, Soeiro OM, Costa KS, Guerra Junior AF, Acurcio FA. Gestão da assistência farmacêutica na atenção primária no Brasil. Rev Saude Publica 2017; 51(Supl. 2):15s.

44. Brasil. Resolução no 1 , de 29 de setembro de 2011. Estabelece diretrizes gerais para a instituição de Regiões de Saúde no âmbito do SUS (SUS), nos termos do Decreto No 7.508, de 28 de junho de 2011. Diário Oficial da União, Brasília, DF, 07 dez. 2011. Seção I, p. 40.

45. Brasil. Ministério da Saúde (MS). Agência Nacional de Vigilância Sanitária. Resolução-RDC no 44, de 17 de agosto de 2009: Dispõe sobre Boas Práticas Farmacêuticas para o controle sanitário do funcionamento, da dispensação e da comercialização de produtos e da prestação de serviços farmacêuticos em farmácias e drogarias e dá outras providências. Brasília: MS; 2009.

46. Brasil. Ministério da Saúde (MS). Lei no 8.142, de 28 de dezembro de 1990. Dispõe sobre a participação da comunidade na gestão do Sistema Único de Saúde e sobre as transferências intergovernamentais de recursos financeiros na área da saúde e dá outras providências. Brasília: MS; 1990.

Artigo apresentado em 21/07/2020

Aprovado em 06/05/2021

Versão final apresentada em 08/05/2021

Editores-chefes: Romeu Gomes, Antônio Augusto Moura da Silva 